Portland State University

PDXScholar

1976

\title{
Listener Perception of Fluent, Breathy, and Imprecisely Articulated Speech of Stutterers
}

Diane Carol Campbell

Portland State University

Follow this and additional works at: https://pdxscholar.library.pdx.edu/open_access_etds

Part of the Speech and Hearing Science Commons, and the Speech Pathology and Audiology Commons

Let us know how access to this document benefits you.

\section{Recommended Citation}

Campbell, Diane Carol, "Listener Perception of Fluent, Breathy, and Imprecisely Articulated Speech of Stutterers" (1976). Dissertations and Theses. Paper 2335.

https://doi.org/10.15760/etd.2332

This Thesis is brought to you for free and open access. It has been accepted for inclusion in Dissertations and Theses by an authorized administrator of PDXScholar. For more information, please contact pdxscholar@pdx.edu. 
AN ABSTRACT OF THE THESIS OF Diane Carol Campbell for the Master of Science in Speech Communication: Emphasis in Speech Pathology/Audiology, presented May 5, 1976.

Title: Listener Perception of Fluent, Breathy, and Imprecisely Articulated Speech of Stutterers.

APPROVED BY MEMBERS OF THE THESIS COMMITTEE:

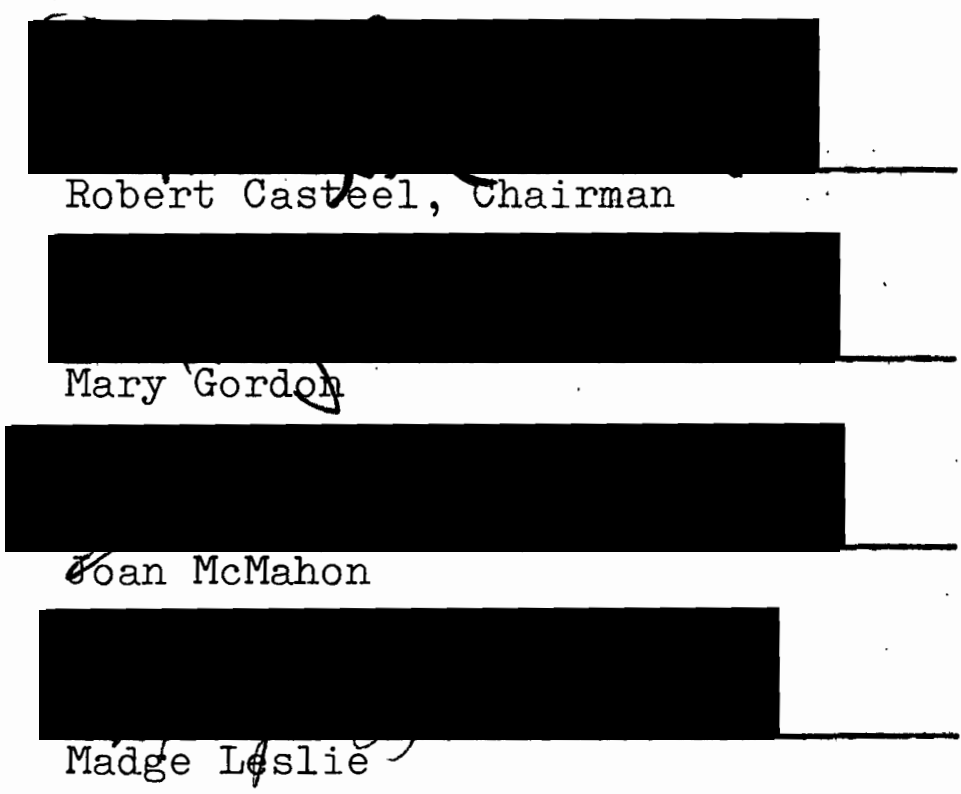

Because communication involves both a sender of messages and a receiver of messages, each person could influence the other's feelings about speaking and listening. The reactions of each member of this communication network will determine how communication will flow in the future. With an understanding of the feedback system between speakers and listeners, researchers have designed management programs 
which allow the speaker who stutters to develop a new pattern of speech which does not hinder his communication efforts. Fluency is the primary consideration, and normalcy of speech is second. One such program has been devised by Casteel (1974).

In Casteel's stuttering management program a person moves through four stages of speaking to be fluent. The client learns to sacrifice specific components of speech and these components are systematically reinstated while fluency in reading, monologue, and dialogue are maintained.

Specifically, the purpose of this study was to determine if breathy and imprecisely articulated speech (Stage III) interferes with the speaker's ability to communicate. The questions to be answered by this study were:

1. Will the use of breathy and imprecisely articulated speech (Stage III) interfere with the listener's ability to communicate with that speaker?

2. Do listeners perceive Stage III speech to be as pleasant as "normal" speech?

3. Do listeners find specific voice characteristics of Stage III speech (breathiness and imprecise articulation) attributed to their rating of "unpleasant"?

The experimental subjects were seven adult male "stutterers" who had received instruction in Casteel's stuttering management program and were judged to use a "good" or "excellent" fluent Stage III. The control subjects were seven male "normal" speakers who were rated 
by trained judges as displaying normal vocal characteristics. The control group was matched for age and occupation of each subject in the experimental group.

The subjects were tape recorded while reading a passage from Narcissus and Goldmund (Hesse 1968) and the recordings were dubbed onto a second tape in a sequence determined by entry into a table of random numbers.

Listeners, who represented a wide variety of backgrounds, occupations, and ages, evaluated each speaker on (1) his/her ability to communicate with that speaker, (2) the pleasantness of the speaker's voice on a scale of one to five, and (3) the specific characteristics that attributed to their rating of four or five on the "unpleasantness" side of the scale.

The findings indicated that naive listeners have more difficulty communicating with Stage III speakers than normal speakers and that listeners do not find Stage III speech to be as pleasant as normal speech at a statistically significant level. Iisteners, were also able to identify the specific characteristics of Stage III speech (breathiness and imprecise articulation) from other non-Stage III characteristics at a statistically significant level. When dividing the homogeneous sample into heterogeneous groups of sex, age, and occupation, Stage III speakers were still viewed to be more difficult to communicate with than "normal" speakers within each group. 
IISTENER PERCEPTION OF FLUENT, BREATHY, AND IMPRECISELY ARTICULATED SPEECH

OF STUTTERERS

\author{
by \\ DIANE CAROL CAMPBELI
}

\begin{abstract}
A thesis submitted in partial fulfillment of the requirements for the degree of

MASTER OF SCIENCE IN SPEECH COMMUNICATION: EMPHASIS IN SPEECH PATHOLOGY/AUDIOLOGY
\end{abstract}

Portland State University 1976 
TO THE OFFICE OF GRADUATE STUDIES AND RESEARCH:

The members of the Committee approve the thesis of

Diane Carol Campbell presented on May 5, 1976.

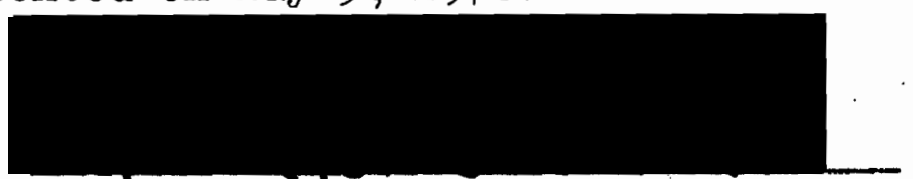

Robert Casteel, Chairman

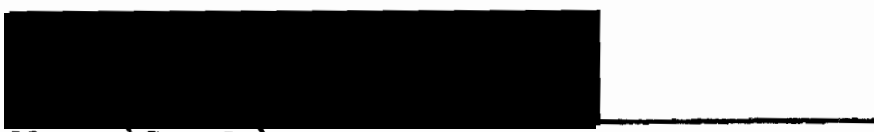

Mary Gordeb

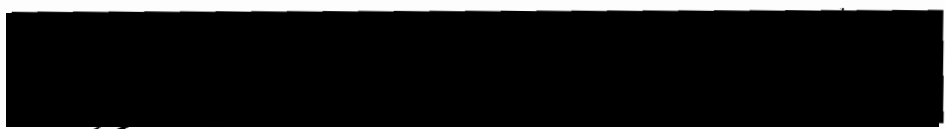

JZan McMahon

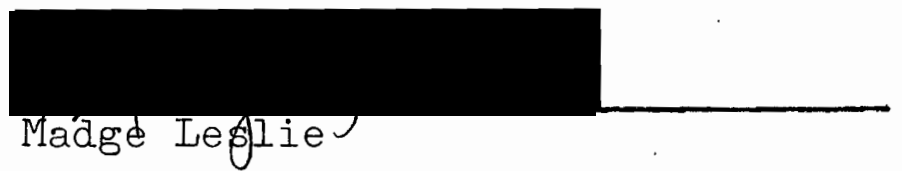

APPROVED :

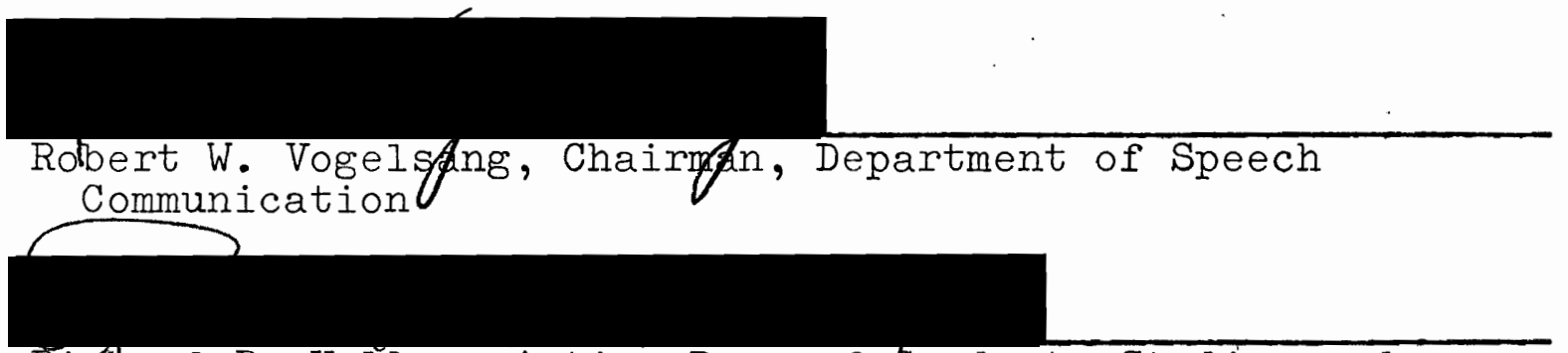

Richard B. Halley, Acting Dean of fraduate Studies and
Research

May 18, 1976 


\section{ACKNOWIEDGMENTS}

Sincere appreciation is expressed to my chairman, Dr. Robert I. Casteel, for his innumerable contributions and supportive encouragement throughout this study. With his dedicated and successful efforts to the area of stuttering within the field of Speech Pathology, this study. was made possible.

Gratitude is also acknowledged to Mary Gordon and Joan McMahon, who also gave of their time, energy, and support to aid in the completion of this study. Many thanks to Dr. Jack R. Hegrenes for his help with the statistics. My family deserves immeasurable appreciation for their continual encouragement, patience, and understanding during my efforts to complete this study.

Also, a genuine thanks to my friends who were understanding when I was "just too busy" to share time with them and also for their continuous inspiration of my efforts. 
TABIE OF CONTENTS

PAGE

ACKNOWLEDGMENTS . . . . . . . . . . • . •

IIST OF TABLES .............. . . . . vi vi

LIST OF FIGURES . . . . . . . . . . . . vii vi vi

CHAPTER

I BACKGROUND AND INTRODUCTION

Statement of Purpose ....... ?

Definition of Terms . . . . . . 8

II REVIEW OF THE IITERATURE . . . . . . . . 9

Background of Stuttering Management Programs

Casteel's Stuttering Management Program

Perkins' Stuttering Management Program

Comparison of Casteel's with Perkins' Stuttering Management Program

Listener's Perception of Fluent Speech of Stutterers vs "Normal" Speech

Iistener's Perception of Breathiness

The Use of Imprecise Articulation

Summary

III METHODS AND PROCEDURES . . . . . . . .

Methods . . . . . . . . .

Selection of Subjects

Instruments

Inter-Judge Reliability

Iisteners 
CHAPTER

PAGE

Procedures • • • • • • • • • • • •

35

Recording Procedures

Setting

Instructions to Iisteners

Statistical Analysis of Data

IV RESUITS AND DISCUSSION • • • • • • • • • •

Results •. •. •. • . . • • •

39

Discussion . . . . . . . . . . . 43

V SUMMARY AND IMPIICATIONS • : • • • • • • • 53

Summary •. •. . . . . . . . . 53

Implications . . . . . . . . . 55

Clinical

Research

BIBI IOGRAPHY

57

APPEND ICES

61 
IIST OF TABLES

TABLE

PAGE

I Communication Difficulty with Stage' III

Speakers . . . . . . . . . . . 40

II Unpleasantness of Stage III Speech • . • . . 4 I

III Iisteners' Ability, to Identify Stage III

Characteristics . . . . . . . . 43

IV The Percentage of Males and Females Who

Perceived They Would Have Difficulty Com-

municating with Stage III Speakers . . . . 44

$V$ The Percentage Within Age Groups Who Per-

ceived They Would Have Difficulty Com-

municating with Stage. III Speakers . . . 44

VI The Percentage Within Occupation Groups Who

Perceived They Would Have Difficulty Com-

municating with Stage III Speakers . . . . 45

VII Unpleasant Attribute Judgments of Normal

Speakers Out of a Possible 572 Responses

by 52 Iisteners . . . . . . . . 46

VIII Unpleasant Attribute Judgments of Stage III

Speakers Out of a Possible 572 Responses

by 52 Listeners • • • • • • . • • • 47

IX Total Number of Listener Identifications of

Unpleasant Attributes of all Stage III

Speakers . . . . . . . . . . 49 


\section{IIST OF FIGURES}

FIGURE

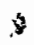

PAGE

1 Trade-offs in Learning Fluency Skills... . 18

2 Normal Speech Dimension Ratings. . . . . 23 


\section{CHAPTER I}

\section{BACKGROUND AND INTRODUCTION}

The terms "stuttering" and "normal nonfluency" express judgments made by listeners. There is no test for determining the precise point at which speech repetitions stop being "normal" and become "stuttering" (Bloodstein 1970). Thus, a definition of the act of stuttering not only includes the speaker's dysfiluency, but also the way in which he and his listeners react to these dysfluencies. Johnson (1955) regarded stuttering as the child's effort to avoid normal nonfluencies. He believed that most normal young children speak with a considerable amount of repetition and other breaks in fluency. Adults differ in their. standards of fluency and some react to the hesitant speech of their children with unusual intolerance. When these children are taught by overanxious adults to feel tense and fearful about their normal nonfluencies, they consequently begin to struggle and strain in their communication efforts in hopes of avoiding these nonfluencies (Johnson 1955). The word "stuttering" is commonly employed to describe behaviors which are done by a speaker; however, each listener seems to attach a different meaning to this term. The attempt to establish estimates of listener fluency standards. 
has been the subject of numerous investigations, Bloodstein, Jaeger, and Tureen (1952) asked parents of young stutterers and parents of young nonstutterers to diagnose the recorded spontaneous speech samples of twelve children, unknown to them, as "stuttering" or "normal." Half of the children in the study were regarded by their parents as stutterers and the other half were regarded as "normal." The parents of stutterers diagnosed both stuttering and nonstuttering children as stutterers significantly more frequently than. the parents of nonstutterers. This discrepancy not only supports Johnson's view of stuttering, but also indicates that listeners vary, in their judgment of "stuttering." In a study (Williams and Kent 1958) to determine whether listeners are likely to classify six different kinds of speech interruptions as "stuttered" when instructed to listen for stuttered interruptions and, conversely, more likely to classify the same interruptions as "normal" when instructed to listen for normal interruptions, researchers concluded that listeners tended to "hear" the kinds of interruptions for which they were instructed to listen. Syllable repetitions and prolongations were consistently identified as "stuttering," while revisions were more consistently responded to as "normal."

Boehmler (1958) instructed three groups of listeners to classify each of 804 tape-recorded speech samples, 402 selected from the speech of stutterers and 402 selected from 
the speech.from normal speakers, as either being an example of stuttering or nonstuttering. Two of his groups of listeners were trained in speech pathology at two different universities and one of his groups was comprised of lay listeners. One of the groups of trained clinicians classified significantly more of the dysfluencies as "stuttering" than did the other trained group, and both groups of clinicians regarded significantly more of the dysfluencies as "stuttering" than did the lay listeners. This study confirmed the findings of Williams and Kent (1958) in revealing that sound and syllable repetitions were labeled as stuttering more often than revisions and interjections. As evidenced by these two studies, there appears to be considerable variation among listeners in classifying dysfluencies as either "stuttering" or normal breaks in fluency. Supporting these studies is a study concerned with the reactions of kindergarten and second grade children to two different types of dysfluency, namely interjections and repetitions, employed systematically by teachers in telling stories. Giolas and Williams (1958) found that syllable repetitions appeared to be less acceptable to the children than were interjections of vowel sounds such as "ah."

The number of units per repetition may constitute an important criterion for many listeners in differentiating "stuttering" from "normal dysfluency." Sander (1963) interviewed 240 college subjects concerning their reactions to 
the occurrence of single (Sa-Saturday) or double (Sa-SaSaturday) unit syllable repetitions in the tape-recorded message of an adult male. Results indicated if a speaker uses a double rather than a single pattern of repetition of a syllable, his speech will more likely be judged as defective and that he will be judged as a stutterer. Additionally, a speaker can use up to eight single syllable repetitions per one hundred words before listeners will label the dysfluencies as stuttering rather than nervousness or a loss of words.

The speech fluency expectations of listeners seem to vary with each listener; however; research (Boehmler 1958, Williams and Kent 1958) has documented that listeners usually identify syllable repetitions and prolongations more often as "stuttering" than revisions and interjections.

Stuttering requires both a speaker and a listener (Sheehan 1968). When a stutterer is alone he reports little, if any, stuttering (Sheehan 1968). He is more likely to stutter when he feels low in self-esteem, and least likely to stutter when he feels high in self-esteem. He is most likely to stutter when he is in awe of the listener, when the listener is a significant other person, when there is some conflict in the relationship, or when there is threat of penalty for stuttering (Sheehan 1968). To study the effect of authority "role-demand," 32 adult stutterers read passages to authority listeners and to peer listeners 
(Sheehan, Hadley, and Gould 1967). Authority listeners were Ph. D faculty members introduced by title and peer listeners were fellow college students introduced by first name. The findings of this study were that stutterers have more difficulty speaking to authority listeners, and that they demonstrated difficulty adapting to them over time. Another study by Berwick (1955) indicated that stutterers showed a significant increase in stuttering during oral reading when the subjects read to the front-view photograph of a person identified by the stutterer as a "hard listener" as compared to viewing the photograph of an "easy listener." Steer and Johnson (1936) found that the least stuttering occurred in situations in which there was either a familiar audience (of one person) or no audience at all. The most stuttering occurred in situations in which the audience was unfamiliar or relatively large (two to at least eight persons). Stuttering appears to vary as a function of the perceived status of the self, the speaker, and of the significant other, the listener.

Successful communication always involves a receiver as well as a sender of messages. A constant flow of visual, verbal, and gestural feedback information tells the sender he is being heard and understood. When these signals cease or do not seem appropriate, fluency breaks and hesitations tend to appear (Van Riper 1973). To determine if the nonverbal responses of listeners are altered when a speaker 
stutters, Rosenberg and Curtiss (1954) used a normal speaker, who simulated stuttering, to speak with subjects who were waiting for a psychology experiment. The findings of this experiment indicated that when the speaker stuttered, there was an increased duration of loss of listener eye contact, a decreased frequency with which hand movement was initiated, and decreased total duration of other bodily movement.

Rarely is the speaker who stutters aware of the actual feelings of his listeners. A study by McDonald and Frick (1954) sought to determine how one group of listeners composed of store clerks felt while talking with a stutterer. After having been asked a question by a severe stutterer, the store clerks reacted with a written response. The data indicated that feelings of impatience, amusement, and repulsion on the part of the listener will be encountered only rarely by the stutterer, while feelings of surprise, embarrassment, pity, curiosity, or sympathy will be expressed by the listener.

Listener reactions to dysfluency conceivably can contribute to the speaker's, evaluation of himself as a stutterer. Iisteners tend to evaluate a stutterer's disorder in the same way the stutterer does (Van Riper 1973). If a stutterer's. reaction to his stuttering indicates that he feels it is distressing and shameful, his listeners will also accept this evaluation. Conversely, if a stutterer's reaction to his speaking shows little distress, the 
listeners also will eventually share that judgment. Within limits, a stutterer can shape the attitude of his listeners, and as a result, spare himself some rejection and punishment (Van Riper 1973).

Several stuttering management programs have been devised to instruct the person who stutters what he needs to do to be fluent. Although he will not be using "normal" speech and will be fluent, he will not be stuttering. The positive or negative reactions of listeners to his fluent way of talking may determine whether he will choose fluency. Because of the dynamic interaction between the speaker and listener, the listener's reaction to a stutterer's way of speaking may determine the flow of communication in future interactions for both members of this communication network. Understanding listener reactions to fluent, but not "normal" speech, will help the stutterer in making choices about the way he speaks.

\section{STATEMENT OF PURPOSE}

The purpose of this study was to determine if breathy and imprecisely articulated speech interferes with the speaker's ability to communicate.

The questions to be answered by this study were:

1. Will the use of breathy and imprecisely articulated speech (Stage III) interfere with the listener's ability to communicate with that speaker?

2. Do Iisteners perceive Stage III speech to be as pleasant as "normal" speech? 
3. Do listeners find specific voice characteristics of Stage III speech (breathiness and imprecise articulation) attributed to their rating of "unpleasant"?

\section{DEFINITION OF TERMS}

The following terms used throughout this study are more specifically defined below:

1. Operant conditioning. The process by which previously neutral stimuli become associated with a reinforcement and thereby increases the probability of a response or a class of responses.

2. Delayed auditory feedback. An instrument by which speech is returned to a speaker's ears a fraction of a second after the time it would normally arrive.

3. Nonstutterer. A person who does not stutter or does not have a history of stuttering.

4. Interference. An interruption of the forward flow of air for speech due to inappropriate tension brought to a segment of the speech musculature. Such interferences include a hard attack and/or stoppage on a sound or syllable and/or repetition and/or prolongation of a sound or syllable. Interferences may be present in "normal" speech.

5. Dysfluency. Same as interference. 


\section{CHAPTER II}

\section{REVIEW OF THE IITERATURE}

Background of Stuttering

Management Programs

Traditionally, emphasis on the management of stuttering has dealt with modifying and shaping the form of a person's stuttering so that stuttering may occur without impairing the stutterer's communication ability or contribute to the maintenance of stuttering. Van Riper (1963) is principally. responsible for developing and teaching this fluent form of stuttering. Five techniques are used in his management program: cancellation, pull-out, prolongation, bounce, and light contact. Cancellation involves repeating a stuttered. word after a short pause ideally in slow motion with prolonged sequence of sounds. It is slower, stronger, spoken more carefully and consciously (Van Riper 1973). In a pullout, a stutterer first becomes aware of his inappropriate contact and then voluntarily prolongs this abnormal posture. Slowly he shifts to a more normal expenditure of energy and does not attempt to complete the word until the normal synergy of movement can be reinstated. Using the prolongation technique, the stuttered sounds are lengthened. A repetitive form of easy stuttering (tension free) with no significant pause between syllables is characteristic of the bounce. 
In a study of the social acceptability of the techniques of pull-out, prolongation, and bounce by Berlin and Berlin. (1964), listeners rated pull-out the highest, followed by prolongation with bounce rated the least desirable. Stutterers and clinicians preferred pull-out also to the other patterns, but rated bounce significantly more acceptable than the lay listeners.

Using light contact, the person who stutters strives for proper coarticulation and for smooth shifts in the motoric sequences, rather than sudden jerky ones. If his tongue or lip contacts are very hard and tight, he should attempt to loosen them. He must be trained to recognize what he is doing motorically and to compare that motor output against the standard pattern of a normal utterance. Even though the first syllable may be slightly prolonged, or the transition is elongated, or an easy, unforced single syllable repetition is exhibited, no avoidance or struggle behaviors should be present if Van Riper's techniques are properly implemented. Van Riper (1973) does not believe these tiny stutterings interrupt the forward flow of speech and are not sufficiently noticeable to evoke either frustration or listener penalty. Therefore, the person under Van Riper's program should work to modify and to simplify his stuttering and learn to stutter in an easy and effortless way. 
Several researchers.(Ryan 1964, Goldiamond 1965, Curlee and Perkins 1969, Perkins 1973a, Casteel 1974) are attempting to more closely approximate normal speech by teaching a smooth flow of speech, with fluency as their first consideration when dealing with the management of stuttering. If speech is considered a psychomotor response, which is a motor response that occurs under varying or changing psychological circumstances, then maladaptive speech responses are weakened through the use of new speech responses (Gregory $1968)$.

An operant conditioning program employing learning theory was developed by Bruce Ryan (1964) which used modified techniques of Van Riper's program including the identification of stuttering behaviors, the establishment of their modification through cancellation and prolongation and the increase of fluency using the modes of reading, monologue, and conversation. A transfer program was implemented to use fluent speech in a wide variety of speaking situations. A criterion of performance was set for each step and reinforcement was provided after each correct response. Whenever the subjects emitted the designated correct response, a clock, operating manually as a counter, signalled the subjects with a click which indicated a reduction in the length of time they were to read.

Goldiamond (1965) has used delayed auditory feedback in establishing and shaping a new speech pattern during 
oral reading. A novel way of speaking (usually speaking at a very slow rate or with vowel prolongation) is created by delayed auditory feedback. As the stutterer meets a designated criterion of fiuency in his oral reading, the delayed auditory feedback is then systematically reduced by 50 millisecond steps, which permits a concurrent increase in the rate of utterance. At zero millisecond delay, the point at which delayed auditory feedback is eliminated, the new way of speaking approaches normal speech. Attempts are then made to transfer the fluency thus obtained into other speaking situations.

Based upon the modification of procedures that used delayed auditory feedback described by Goldiamond (1965), Curlee and Perkins (1969) implemented the "conversational. rate control" therapy. The stutterer begins conversing with the clinician by speaking under a delayed auditory feedback delay of 250 milliseconds. He is instructed to decrease his speaking rate by prolonging syllables so that his utterances coincide with the delayed feedback. The delay time is reduced by 50 millisecond steps until no. stuttering occurs at a zero delay. Once the client has met the no-stuttering criterion at zero milliseconds delay, he is instructed to use a slow enough articulatory rate and short enough pauses to maintain freedom from instances and expectation of stuttering and is removed from the delayed auditory feedback equipment. A transfer program is then 
jmplemented to ensure the use of fluent speech outside the clirical setting. Some of the subjects sacrificed prosody for fluency by using slow rates with monotonous inflection. According to Curlee and Perkins (19̈73), for severe stutterers this trade-off may have some merit, but not all were willing to accept it; therefore this form of fluency could possibly be more unacceptable to some stutterers and listeners than the original dysfluent speech.

The programs reviewed above dealing with the management of stuttering have not allowed the client to assume responsibility for the way he talks. He has either learned certain "tricks," such as prolongation, cancellation, or pull-out, which enable him to stutter in a smooth, easy manner or has simulated the speech learned on mechanical devices which allow him to "control" his stuttering and speak relatively fluently using a slower rate and prolonged speech. These new speech patterns may not be pleasing to the stutterer or listener, as indicated by Curlee and Perkins (1973). Two programs have been developed recently which enable a person to modify his speech patterns to maintain fluent speech which closely approximates normal speech. One of the two programs allows the person to understand why he has interferred with his speech and thus to modify his speaking patterns to obtain fluency. A discussion of these programs follows. 
Casteel's Stuttering

Management Program

The underlying philosophy of a stuttering management program developed by Casteel (1974) is that the semantic orientation a person develops to understand the way he speaks will influence his success in changing his speaking patterns. "Stuttering" is often a verbal blindfold that keeps the person who stutters from realizing what he is. actually doing to interfere with his speaking (Sander 1970). He often speaks of stuttering as something that "happens" to him, rather than something he "does" (Williams 1957). In essence, he believes that "stuttering" is just "part of him." He is not aware that what he calls his "stuttering" are behavioral responses created by himself and that he himself is solely responsible for these behaviors (Williams 1957).

The person who "stutters" acts as if he believes there is something inside him called "stuttering" that makes the words get stuck in his throat and that makes his breath stop. He thus builds up a variety of special things to do to "help" the word come out or to avoid the "trouble" altogether. He may begin to tense his jaw muscles, hold his breath, or tense his lips in order to "talk without stuttering." These are the things a person does "to interfere with talking," and thus, to interfere with the forward flow of air (Williams 1957). 
The goal is to change the way the speaker talks, and therefore, acts about his speaking so that he does more and more things that most people do when they talk (Williams 1957). Understanding that normal speech involves such characteristics as a general continuity of sound production, a process of moving from sound to sound with no holding of the breathstream and with no excessive tension in the throat, jaw, lips, etc., will help serve as a reference point for changing the things he is doing which interfere with talking.

Based upon this philosophy of stuttering, Casteel has developed a program at Portland State University for the management of stuttering. The philosophical rationale for the use of this program are as follows:

1) hypertensive muscle action characterized interference of air flow in most stutterers; 2) the stutterer has made incorrect choices in the way he talks; 3) he has made these incorrect choices because he is not aware of what he is doing physiologically when he stutters or when he is fluent; 4) the individual, historically, has not taken nor been credited with the responsibility for choosing his speech behavior; and 5) he is capable of learning to be an efficient talker rather than only learning to be an efficient stutterer (Casteel 1974).

Enabling the person who stutters to realize stuttering is something he "does," rather than something that "happens" to him, has been effectively promoted by the use of descriptive, active, and positive language as described by Sander (1970). Descriptive language will enable the person who stutters to know what he is doing when he interferes with 
his talking, such as "I held my lips tightly together and stopped the flow of air." Active language describes what he "did," rather than what "happened" to him. A tongue does not become. "stuck," rather the person tensed some muscles to interfere with the easy movement of the tongue and the flow of air. Such words as "have" and "happen" imply a passive helplessness and discourage the person who stutters from accepting responsibility for his behavior. The use of positive language directs him to do the things that most people do to talk normally, rather than what not to do. A statement such as "I need to let my lips be loose to permit easy air flow" is an example of positive language. As the client learns that he has a choice in how he will use his muscles for speaking fluently, he will begin to assume the responsibility for his speaking. In congruence with Van Riper, Casteel believes the client should know what he is doing motorically so the proper modification can be made in the direction of smooth and fluent speech.

Normal speaking is characterized as being composed of appropriate fluency, rate, loudness, pitch, quality, and articulation (Casteel 1974). Initially, the client is trained to sacrifice, or trade-off, in various degrees all of these components other than fluency. For this reason, these trade-offs are often exaggerated at first to simplify the discrimination task of appropriate and inappropriate muscle tension brought to speaking. 
As the client progresses through the four stages of the program, the above vocal components are systematically reinstated while fluency in reading, monologue, and dialogue are maintained (Figure 1). Specific criteria must be met in each stage before moving to the next stage. The client and clinician develop a hierarchy of stressful situations, in which the client moves through a series of successes in the laboratory and in real life situations, beginning in low stress situations and progressing to high stress ones. Stage I ("Stretch and Flow") is characterized by fluency, prolongation of words using closed juncture, low intensity, monotone, breathy quality, and imprecise articulation. The client primarily uses Stage I in the laboratory. He learns to discriminate between what he does to be fluent and what he does to interfere with his flow of air. Progressive relaxation is introduced in the early stages of management so that he becomes aware of the degree of tension he brings to the task of talking. Over-tension of the speech musculature can interfere with air flow and so he learns to make the appropriate adjustments to permit air to flow.

Stage II ("Increased Breath") is characterized by fluency with normal rate reinstated, but the client maintains increased breathiness, closed juncture, relative monotone, and loose articulation. The client is first successful in using this stage in the laboratory and then he uses it in many low stress situations outside the laboratory. 


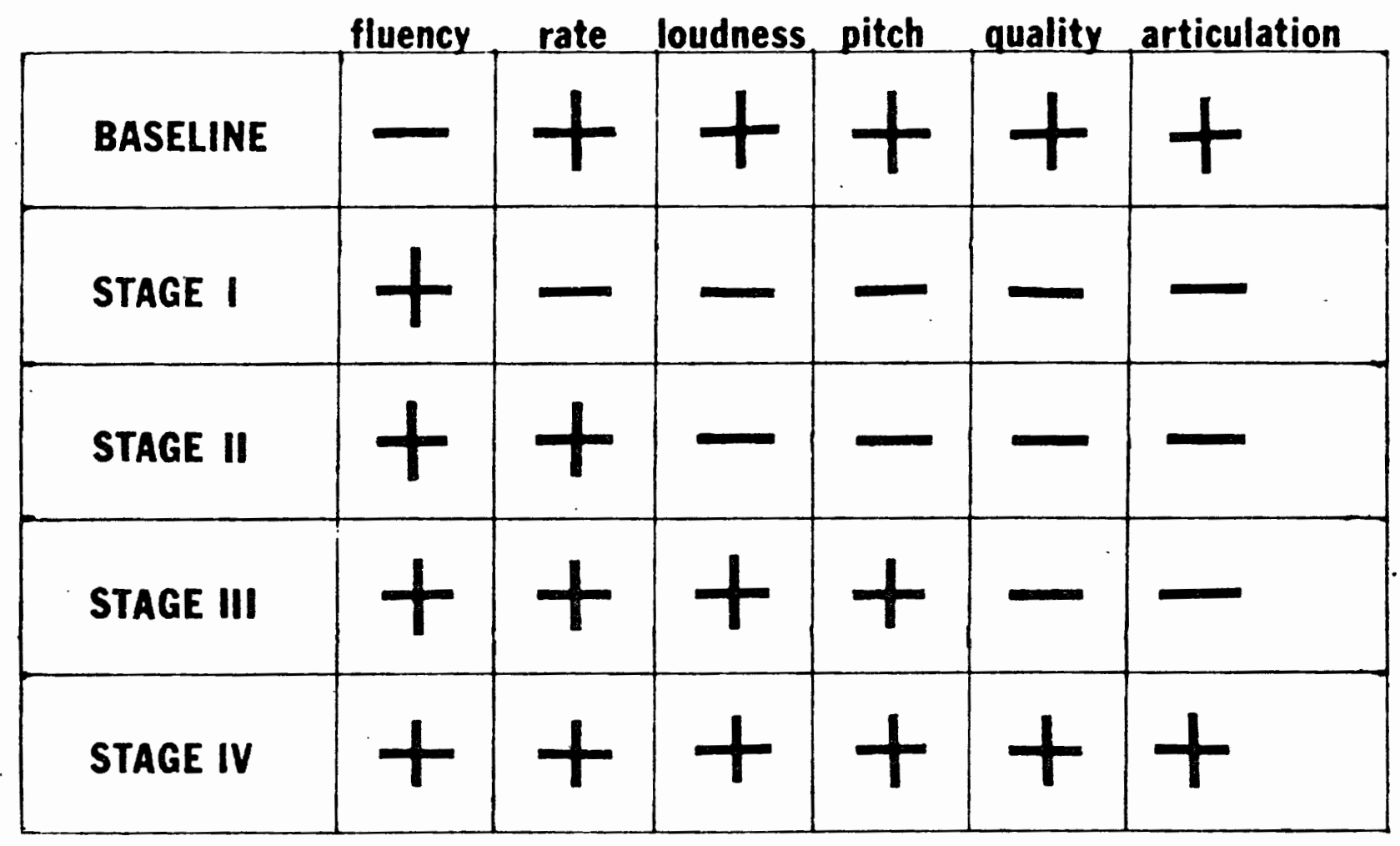

Figure 1. Trade-offs in learning fluency skills. - (Casteel 1974) 
Stage III ("Reduced Breath") is characterized by fluency with loudness and vocal variety reinstated while maintaining normal rate, but the voice remains somewhat breathy and there is imprecise articulation. The client is talking in Stage III outside the laboratory in middle and high stress situations. Casteel (1974) observes that Stage III is attractive to the client because normal rate, loudness, and vocal variety have been reinstated. The client is now able to make subtler adjustments in air flow and associated speech muscle tensions. Additionally, the remaining trade-offs (breathiness and imprecise articulation) tend not to call attention to the speech, for the sacrifices are minimal.

In Stage IV ("Easy Talking") all components are reinstated. In this stage the person still has the option or choice of talking anytime in Stage III or II because of a dysfluency or a general uneasiness in a situation. These choices enable him to do the things he needs to do to talk easily and fluently. When the clinician observes that the client is taking responsibility for his talking and is making the appropriate choices to maintain fluency, clinical contact is faded and the client is ready for self-maintenance.

Perkins' Stuttering Management Program

A program for the management of stuttering that is similar in some aspects to Casteel's stuttering management program is that of Perkins, Speech Pathologist at University 
of Southern California. This program is an outgrowth of conversational rate control therapy (Curlee and Perkins 1969). Perkins et al. (1974) found that when the newly acquired speech patterns approximate "normal" speech, these speech patterns are maintained for a greater length of time. Their observations agreed with Andrews and Ingham's (1971b) that fluency alone is not sufficient to insure normal speech; normal rate and prosody are also required. Andrews and Ingham believe successful treatment should enable a client to speak normally and to use this speech to interact with his environment in the same way normal speakers do. The criteria for successful treatment are: (1) the speech must be within normal limits, including no multiple repetitions, blocks, prolongations or associated body movements and no tension to interrupt the smooth flow of speech, (2) normal nonfluencies of speech should be minimal, should increase with fatigue or with excessive stress, and should be under voluntary control, as with other normal speakers, (3) rate of speech should be under voluntary control, and it should be variable within wide limits, and (4) pitch, loudness, and rhythm should be normal. With this evaluation of the successful outcome of stuttering management in mind, Perkins' most recent program is based upon the premise that if a person's speech "breaks down," he needs to know what he must control to get the flow of speech back to normal. The factors necessary to shape normal speech include fluency, rate, breathstream, prosody, 
and self-confidence (Perkins 1973a). When a dysfluency occurs, it reflects the failure to achieve at least one, if not all, of the other components of normal speech (Perkins 1973a).

Maintaining normal speech requires confidence in being able to speak easily (Perkins 1973a). The initial objective of Perkins' program is to achieve normal speech in slow motion (250 milliseconds of delayed auditory feedback) by moving through Goals I, II, and III. Once normal speech in slow motion is shaped, the rate of progression from Goal IV through subsequent goals is determined by the stutterer. He should proceed to the next step only when he is comfort able with his speech at the slow rates required by delayed auditory feedback and more importantly, when he is confident he can maintain normal speech flow without uneasiness or uncertainty (Perkins 1973b).

The specific goals of Perkins' program are as follows (Perkins 1973b):

Goal I: Establish Fluent Speech (using 250 milli. seconds delayed auditory feedback)

Goal II: Establish Normal Breath Flow

Goal III: Establish Normal Prosody

Goal IV: Shift Responsibility for Talking at. Subsequent

Steps to Stutterer

Goal V: Establish Slow-Normal Speech in Conversation

Goal VI: Incorporate Psychotherapeutic Discussion

Goal VII: Establish Normal Speech Rate

Goal VIII: Establish Normal Speech Without Delayed

Goal IX: Auditory Feedback

As the client begins to transfer his speech to daily living situations, he evaluates his speech during each 
session using the Normal Speech Dimension Ratings form (Figure 2) to determine if his speech is approximating normal speech.

The procedures for generalizing normal speech in Perkins' program are as follows (Perkins 1973b):

Goal I: Prepare the Stutterer to Recover Normal Speech When It Is Disrupted or When Disruption Is Anticipated

Goal II: Extend Stimulus Control of Normal Speech to Daily Life

Goal III: Facilitate Living Pattern Changes to Foster Permanence of Normal Speech

\section{Comparison of Casteel's with Perkins'}

Stuttering Management Program

As in conversational rate control (Curlee and Perkins 1969), fluency is achieved in the Perkins' program by using 250 milliseconds of delayed auditory feedback. The client initially speaks at about 50 syllables per minute and his rate is increased as the other dimensions of normal speech are achieved and maintained. Slow rate is a means of facilitating coordination of phonation with articulation. The prime objective is to establish confidence that when the breathstream flows smoothly and continuously, speech is easy and effortless (Perkins 1973a). The client is dependent on delayed auditory feedback for the first seven goals of the program; the responsibility for fluent speech then shifts to the client. In Casteel's program, the client assumes responsibility for his talking from the first clinical 
NORMAL SPEECH DIMENSION RATINGS

Fluency

\section{(1) Optimal \\ Exceptionally \\ Fluent}

(4-)

Abnormal

\begin{tabular}{|c|}
\hline bnormal \\
\hline Very \\
\hline
\end{tabular}

Clear and Smooth

(1) Optimal

Exceptionally

Expressive

(1) Optimal

Alwoys Certain of

Smooth, Easy Speech

(2)
$\begin{aligned} & \text { Fluent, with Normal } \\ & \text { Hesitations }\end{aligned}$

Rate

(I)

$\frac{(2-)}{\text { Normally }}$
Slow

Optimal

$\frac{(2+)}{\text { Normally }}$

$(3+)$

Too

Fast

$\frac{\text { (4) Abnormal }}{\text { Severe Stuttering }}$

Normally
Slow

Breath Flow: Voice

(2)

Breathy and

Smooth

Breathy and

Choppy

Prosody

(2)

$\overline{\text { Expressive }}$

(3)

$\overline{\text { Monotonous }}$
$(4+)$

Abnormal Very

Fast
(4) Abnormal Constricted and Sticky

(4) Abnormal Exceptionally Monotonous

(4) Abnormal Expect to Struggle and Stutter

Figure 2. Normal Speach Dimension Ratings. (Perkins 1973b) 
session and does not establish fluency through the use of mechanical equipment. Rate is the first dimension to be reinstated in Casteel's program, while speech continues to be smooth and effortless. The client will thus become confident that he can be fluent at a normal rate of speaking.

Normal prosody is maintained even at the slowest rates in Perkins' program. Perkins (1973b) believes that if fluency is achieved with monotone at slow rates, then monotone is usually required as one of the conditions necessary to maintain fluency at faster rates; therefore, monotone speech is not introduced. Monotone is one of the speech dimensions present in Casteel's program until Stage III speech. Vocal variety is then reinstated in Stage III speech, while the client maintains fluency. This is contrary to Perkins' belief that clients will expect monotone to be a necessary ingredient for fluency.

The proper management of breathstream is an essential element in Perkins' program. This management involves the use of a soft vocal attack in which the vocal folds are relatively relaxed to initiate phrases, maintenance of a continuous air flow through the phrase, and vocal production that is free of constriction, or tightness in the throat (Perkins 1973a). In the Casteel program exaggerated breathiness is defined by -2 on the Openness of the Laryngeal Cavity scale on the Jewish Hospital Voice Profile. Exaggerated breathiness is used in Stages I and II to simplify the 
discrimination task of appropriate or inappropriate muscle tension brought to speaking. The breathiness is reduced somewhat in Stage III speech, as the client approximates normal speech and maintains his fluency. At this point he is beginning to learn to use the proper amount of muscle tension necessary to produce a smooth flow of air, resulting in fluent speech.

Perkins allows easy repetitions to occur, which are characteristic of normal dysfluency. Ideally, each phrase should have sufficient continuity in the air flow of the voice stream and would sound almost as if a continuous hum were going through the speech without any breaks in the air flow (Perkins 1973c). In contrast, if a person interferes with his speech, Casteel believes the person is interrupting his air flow by bringing inappropriate tension to the task of talking. This is an indication that he needs to modify one or perhaps more of the dimensions of normal speech to reestablish fluency. Dysfluencies are referred to as "hard attacks" by Perkins and he feels they are the major difficulty the stutterer has in the management of his normal speech flow. (Perkins 1973c).

Both Casteel and Perkins manipulate the dimensions of speech to achieve and maintain fluent speech. In Casteel's program, the client learns what he needs to do to talk fluently and is aided by the use of descriptive, active, and positive language. By identifying and describing what he is 
doing when he talks, he accepts responsibility for his talking. The client learns to be fluent in Perkins' program by manipulating rate, breathstream, and prosody. The establishment of the stutterer's confidence that he can speak normally is a paramount prerequisite to the permanence. of the newly acquired fluent speech pattern.

Iistener's Perception of Fluent Speech of Stutterers Vs. "Normal" Speech

Determining whether listeners detect any difference between the fluent speech of stutterers and "normal" speech has been the concern of some researchers. The research is sparse and of opposing conclusions. Wendahl and Cole (1961) presented eight pairs of speakers, each pair containing a fluent stutterer and a normal speaker, to a group of judges who were undergraduate students in psychology. The tapes were edited so the speakers exhibited no dysfluencies. The listeners were asked to identify (1) which of the pair was the stutterer and which was the nonstutterer, (2) which of the pair used a more normal speaking rate, (3) which of the pair used more force or strain while speaking, and (4) which of the pair used a more normal rhythm pattern. The results of this study indicated that (I) stutterers are differentiated from nonstutterers when listeners were asked to listen for a difference, and (2) stutterers have a slower rate of speech, use more force or strain, and have less rhythmical speech patterns than nonstutterers. 
Young (1964) replicated Wendahl and Cole's study (1961), using the same tapes, but slightly different procedures. Thirty listeners, most of whom were graduate students in speech pathology, were asked to judge whether each phrase was spoken by a stutterer or nonstutterer. In this study, listeners did not evaluate rate, force of speech, or rhythmic patterns of each speaker, which would provide additional cues in distinguishing between a stutterer and a nonstutterer. Instead of supporting Wendahl and Cole's conclusion, Young found that fluent speech samples of stutterers were not easily differentiated from the speech samples of nonstutterers.

Using 25 fluent stutterers and 25 nonstutterers as their subjects, Love and Jeffress (1971) had each subject read a certain passage. The speech was then analyzed by electronic equipment to determine length of pauses. They found that pauses occur significantly more frequently in the fluent speech of stutterers than of nonstutterers. Love and Jeffress (1971) concluded that "the results of this experiment strongly support the view that a stutterer continues to do something different from the normal, even when he is not stuttering."

Attempting to understand this controversy, Few and Iingwall (1972) conducted a study using 14 adult fluent stutterers and 14 adult nonstutterers to determine if listeners were able to ascertain which speakers were 
stutterers. The listeners were graduate students in speech pathology and audiology. The listeners judged speaking rate, cumulative pause time, and articulation rate on all speakers; none of these measures distinguished stutterers from the nonstutterers at the .05 level of significance.

None of these studies have discussed how the fluent stutterers had achieved fluent speech nor what kind of management program was invoked. Despite this lack of information, it should be noted there have been discrepancies of listener judgments in distinguishing between the fluent speech of stutterers and the speech of nonstutterers.

Perkins et al. (1974) instructed listeners to evaluate the speech of two groups of fluent stutterers, each group having received a different method of treatment. The emphasis with 27 clients in group I was on control of rate to maintain fluency through the use of conversational rate control using delayed auditory feedback. The emphasis with group II, which was composed of 17 clients, was on control of rate to facilitate normal management of the breathstream, phrasing, and prosody, as well as fluency. This group also used delayed auditory feedback to help achieve the desired fluent speech pattern. The method used with group II was Perkins' most recent approach to the management of stuttering, which is similar in some respects to Casteel's program. The listeners, who were undergraduate liberal arts students, evaluated the speakers on the speech dimensions of 
fluency, rate, and prosody. Group I was judged as being slower and less expressive than normal speakers, but as fluent as normal speakers. Listeners judged group II as no different than normal speakers on the basis of fluency, rate, and prosody. This study seems to indicate that what a person specifically learns to do to be fluent may be the determining factor in how listeners perceive his speech as compared to the normal speech of a nonstutterer.

\section{Listener's Perception of Breathiness}

In Stage III speech of Casteel's stuttering management program, all dimensions of normal speech are reinstated, except quality and articulation, in which speech remains somewhat breathy and loose in articulation, but fluency is maintainea. The human voice assumes a breathy quality when the vocal folds fail to approximate completely as they vibrate and/or are overly relaxed, and a steady stream of air rushes through the glottis and resonance cavities (Fairbanks 1940).

The perception of breathiness in the human voice has not been subjected to extensive investigation. In the following studies and observations of breathy quality, the degree of breathiness in the voice of the speakers cannot be determined.

Diehl and McDonald (1956), using one speaker, reported that a simulated breathy voice communicated less information 
to listeners than a voice not exhibiting a breathy quality. A 14-minute lecture on "Birds" was presented to a group of listeners and afterwards, group members completed a response sheet composed of simple recall-type completion questions based on the lecture content and a rating scale in which the voice of the lecturer was judged. The lecture varied in each of the groups in five voice quality types--simulated hoarse, harsh, breathy, and nasal quality, and one free from these. On a pleasantness scale, the breathy voice was rated as "average."

Voice quality is often associated with personality. Addington (1968) found that increased breathiness in the voices of male speakers were rated as being younger and more artistic. Females who simulated increased breathiness were perceived as more feminine, prettier, more petite, and more effervescent, while at the same time were perceived as being shallower (Addington 1968). On the other hand, Fairbanks (1940) notes a "modern tendency in some circles to regard . . the combination of low pitch and breathiness as good voice usage, particularly in women."

Clinically, Fairbanks (1940) stated breathiness is often associated with weak vocal intensity and a lower than optimum fundamental frequency level. Ptacek and Sander (I963) found that perceived breathiness decreased as a function of intensity and increased as a function of frequency. At higher intensity levels, less breathiness was perceived. 
The Use of Imprecise Articulation

Van Riper (1963) used light contact as one of his techniques in the management of stuttering to facilitate proper coarticulation and smooth shifts in the motoric sequences of speech. This technique aided the stutterer in learning to stutter in an effortless and smooth manner. Imprecise articulation, the term by which Casteel refers to "light contact," is used throughout the four stages of his management program and is necessary in facilitating and maintaining smooth air flow and fluent speech even outside the clinical setting.

\section{Summary}

There appears to be a minimal amount of inter-judge reliability in determining what constitutes "stuttering" and what constitutes "normal nonfluency." Listeners seem to be somewhat in agreement in the type of interferences commonly identified as stuttering, namely syllable repetitions and prolongations, while revisions and interjections will more consistently be responded to as "normal."

Because communication involves both a sender of messages and a, receiver of messages, each person could influence the other's feelings about speaking and listening. The reactions of each member of this communication network will determine how communication will flow in the future. The listener may subtly react nonverbally to a speaker who stutters and may feel embarrassment, curiosity, or sympathy 
towards that speaker. The speaker may thus modify his speech patterns in response to his listener's reactions. With an understanding of listener judgment of stuttering and the feedback system between speakers and listeners, researchers have attempted to design management programs which allow the speaker who stutters to develop a new pattern of speech which does not hinder his communication efforts. Traditionally, these programs enabled him to stutter more smoothly and easily, but in later programs, he learned to speak at a slow rate using prolonged words. Listeners still detected this speech pattern as being different from normal speaking, even though speakers were fluent. Researchers then turned toward developing management programs which maintained fluent speech, but more closely approximated normal speech through the emphasis on the management of the breathstream and the manipulation of other dimensions of normal speech. Listeners reacted favorably to this fluent speech of stutterers and the communication system can hopefully begin its interaction again without the speaker directing unnecessary attention to the manner in which he speaks. 
CHAPTER III

METHODS AND PROCEDURES

I. METHODS

Selection of Subjects

Seven "stutterers," who had received instruction in Casteel's stuttering management program, were chosen as experimental subjects for this investigation. All subjects were using Stage III speech fluently in medium and high stress situations or had progressed beyond that point into Stage IV speech or Self-Maintenance. The Stage III speech of speakers were evaluated by three judges trained in using Casteel's stuttering management program (Appendix A). Each judge was to rate a speaker's Stage III speech as "poor," "good," or "excelient." Examples of a "poor" rating given to judges included an inconsistent use of Stage III speech, use of Stage II or IV speech, or inappropriate use of breathiness and imprecise articulation. For a speaker to be chosen as a member of the experimental group all judges had to rate his speech as "good" or "excellent."

The experimental subjects' voices were evaluated by trained judges using sections of the Jewish Hospital Voice Profile developed by Frank B. Wilson (1971) (Appendix B). 
Each Stage III voice was rated "I" on the Resonating Cavity scale, "-2" on the Openness of the Iaryngeal Cavity scale, and $"+2,1$, or -2 " on the Pitch scale.

The subjects were male and ranged in age from 24 to 52 years. One subject was chosen from within each decade of the age range, except in the 20- and 30-year decades, in which two subjects in each decade were selected.

Seven subjects who did not stutter nor had a history of stuttering comprised the control group. They had normal voices, as measured by the Jewish Hospital Voice Profile. A normal voice was rated "I" on the following scales:

Openness of the Laryngeal Cavity, Pitch, Resonating Cavity, Vocal Range, Rate, and Intensity. They were males and were matched for occupation and age within three years of each subject in the experimental group.

\section{Instruments}

The Jewish Hospital Voice Profile was used to select persons who had normal voices for the control group (Appendix C). Portions of this instrument were also used to evaluate the voices of the Stage III speakers (Appendix D). The purpose was to determine if trained judges perceived any deviant voice qualities which may have attributed to listeners' evaluations of an "unpleasant" voice, even though this voice quality may not relate to stage III speech. 
Inter-Judge Reliability

Two faculty members trained in using the Jewish Hospital Voice Profile served as judges to evaluate the voices of the experimental group and the control group.

The Stage III speech of speakers in the experimental group were evaluated by three judges trained in using Casteel's stuttering management program.

\section{Iisteners}

Fifty-two listeners, ranging from 22 to 69 years, evaluated the speakers. They were selected from various service or interest organizations within the Portland vicinity, such as Sertoma, a garden club, and a medical facility and represented a wide variety of backgrounds, occupations, and ages. Upon initial contact, the representative of the group was informed that the researcher was a graduate student in speech pathology at Portland State University and needed some people to listen to and evaluate some taped speakers for a Master's thesis study.

\section{PROCEDURES}

Recording Procedures

Each speaker in the experimental group read a selected passage from Narcissus and Goldmund by Hermann Hesse (1968) (Appendix E). The speakers in the control group read the same passage. Before each speaker was tape-recorded, he was 
allowed to practice the passage aloud. The speakers in the experimental and control groups did not interfere while reading the passage. All 14 voices were tape-recorded at a 5.5 irtensity level using an Artik tape recorder and at a speed of 7-1/2 inches per second. The subjects were seated and spoke approximately 12 to 15 inches from the microphone. Readings from speakers in the experimental group and control group were dubbed onto a second tape in a sequence determined by entry into a table of random numbers.

\section{Setting}

The same tape was administered in various rooms to groups of people at a speed of $7-1 / 2$ inches per second using a Sony TC-106A tape recorder. The maximum number of listeners in each group did not exceed 18. Identical instructions were given to each group and the tape recorder intensity level was set at a comfortable listening level.

\section{Instructions to Listeners}

Each listener was asked to list his/her age, sex, and occupation on a separate sheet prior to receiving instructions about listening to the speakers. The listeners were then given verbal instructions by the researcher about the procedures for listening to the tape prior to hearing the recorded voices (Appendix F). They were then given 14 rating sheets, I for each speaker (Appendix G). Each voice was played 1 time for the listeners. A male voice not included 
within the experimental and control groups was played first so Iisteners could determine a comfortable listening level for the particular room in which they were located.

Section one: Immediately after listening to each speaker, the listener was to make a decision as to whether the speaker's voice would interfere with his/her ability to communicate with that speaker. The specific question asked of the listener was: "Would his speech make it difficult for you to carry on a conversation with this person?" The listener responded by circling "yes" or "no." If he/she responded by circling "yes," the listener was to answer the question: "What aspects of his speech would interfere with being able to carry on a conversation with this person?"

Section two: The next task was to evaluate the speaker's voice on the "very pleasant" to "very unpleasant" scale of one to five. If the listener rated the speaker four or five on this scale, he/she was to complete section three of the form at that time.

Section three: The listener made judgments about specific characteristics of the speaker's voice as to why he/she found the speaker's voice "unpleasant" to listen to. Such voice characteristics included too loud, too soft, monotone, somewhat whispered, pitch too high, pitch too low, somewhat nasal voice, unclear speech, speaks too fast, speaks too slow, and somewhat hoarse voice. Out of the multiple foils, the voice characteristics of "somewhat 
whispered" and "unclear speech" were specific to Stage III speech. The listener checked the specific voice characteristic or characteristics which accounted for his/her original negative reaction to the speaker's voice.

\section{Statistical Analysis of Data}

Chi Square was used to establish whether or not the use of breathy and imprecisely articulated speech (Stage III) interferes with the listener's ability to communicate with that speaker at a statistically significant level.

In determining if listeners perceive Stage III speech to be as pleasant as "normal" speech, Chi Square was used to establish significance. Ratings of "I" and "2" were placed in a "pleasant" category, "3" in a "medium" category, and "4" and "5" in an "unpleasant" category.

Chi Square was also used to determine if listeners identified the specific voice characteristics of Stage III speech (breathiness and imprecise articulation) as attributing to their rating of "unpleasant" at a statistically significant level. The two specific characteristics of Stage III speech on the evaluation sheet (somewhat whispered and unclear speech) were placed in one group and the other nonStage III characteristics listed were placed in the other group. 
CHAPTER IV

\section{RESULTS AND DISCUSSION}

\section{RESUITS}

The purpose of this investigation was to determine if breathy and imprecisely articulated speech interferes with the speaker's ability to communicate. To determine a speaker's ability to communicate using Stage III speech, listeners reacted to this speech pattern by evaluating the speaker on their perceived ability to communicate with him and the pleasantness of the speaker's speech. The speaker's communication ability was thus inferred from the data obtained of the listeners' ability to communicate with that speaker. Fifty-two listeners evaluated the voices of seven "normal" speakers, comprising the control group, and seven speakers whose speech was breathy and imprecisely articulated (Stage III), who comprised the experimental group. Specifically, the questions to be answered by the study were:

1. Will the use of breathy and imprecisely articulated speech (Stage III) interfere with the listener's ability to communicate with that speaker?

2. Do listeners perceive Stage III speech to be as pleasant as "normal" speech?

3. Do listeners find specific voice characteristics of Stage III speech (breathiness and imprecise articulation) attributed to their rating of "unpleasant"? 
To determine if the use of breathy and imprecisely articulated speech (Stage III) interferes with the listener's ability to communicate with that speaker, Chi Square was used on the results of the speaker evaluations. As seen in Table I, the listeners of this study would have difficulty communicating with speakers using breathy and imprecisely articulated speech at a statistically significant level $(\mathrm{p}<.001)$. Of 726 total responses by 52 listeners, 248 responses indicated difficulty communicating with Stage III speakers as compared to 22 for "normal" speakers; there were 115 responses indicating not having difficulty communicating with Stage III speakers as compared to 341 for "normal" speakers. There were two unmarked responses by listeners for this section.

TABLE I

COMMUNICATION DIFFICULTY WITH STAGE III SPEAKERS

\begin{tabular}{l|c|c|c}
\hline \multirow{4}{*}{ Stage III } & yes & no & Total \\
\cline { 2 - 4 } Normal & 248 & 115 & 363 \\
\multirow{2}{*}{ Total } & 22 & 341 & 363 \\
\cline { 2 - 4 } & 270 & 456 & 726 \\
\hline
\end{tabular}
$x^{2}=301.18, p<.001$, d. $f=1$

To determine whether the listeners perceive Stage III speech to be as pleasant as "normal" speech, Chi Square was 
used. Ratings of " 1 " and "2" were placed in a "pleasant" category, "3" in a "mediam" category, and "4" and "5" in an "unpleasant" category. Table II reveals that the listeners perceived Stage III speech to be more unpleasant than "normal" speech at a statistically significant level $(\mathrm{p}<.001)$. Of 724 total responses by 52 listeners, 3 responses indicated Stage III speech to be pleasant to listen to as compared to 179 for "normal" speech; there were 27 responses indicating Stage III speech to be "medium" to listen to as compared to 140 responses for "normal" speech; and there were 332 responses indicating Stage III speech to be "unpleasant" as compared to 43 responses for "normal" speech. There were 4 unmarked responses by listeners for this section.

\section{TABLE II}

UNPIJEASANTNESS OF STAGE III SPEECH

\begin{tabular}{l|c|c|c|c}
\hline \multirow{2}{*}{ Stage III } & Pleasant & Medium & Unpleasant & Total \\
\cline { 2 - 5 } Normal & 3 & 27 & 332 & 362 \\
Total & 179 & 140 & 43 & 362 \\
\cline { 2 - 5 } & 182 & 167 & 375 & 724 \\
\hline \multicolumn{2}{c}{$\mathrm{x}^{2}=441.40, \mathrm{p}<.001$, a.f. $=2$}
\end{tabular}

Chi Square was also used to determine if the listeners identified the specific voice characteristics of Stage III speech (breathiness and imprecise articulation) as attributing 
to their rating of "unpleasant." Table III reveals the listeners were able to distinguish breathiness and imprecise articulation (listed as somewhat whispered and unclear speech) as Stage III characteristics from other non-Stage III characteristics (listed as too loud, too soft, monotone, pitch too high, pitch too low, somewhat nasal voice, speaks too fast, speaks too slow, and somewhat hoarse voice) at a statistically significant level. $(\mathrm{p}<.001)$. Of 901 total responses by 52 listeners in identifying the specific characteristics related to the "unpleasantness" of Stage III speech, 318 responses identified the two specific Stage III characteristics and 583 responses identified the non-Stage III characteristics. Of 76 total responses by 52 listeners reacting to the "unpleasantness" of "normal" speech, 2 responses identified the two specific characteristics as unpleasant attributes of "normal" speech and 74 responses of non-Stage III characteristics were attached to the unpleasant attributes of "normal" speech. 
TABLE III

LISTENERS' ABILITY TO IDENTIFY

STAGE III CHARACTERISTICS

\begin{tabular}{l|c|c|c}
\hline & Stage III & Normal & Total \\
\cline { 2 - 4 } & 318 & 2 & 320 \\
$\begin{array}{l}\text { Stage III } \\
\text { Characteristics } \\
\begin{array}{l}\text { Non-Stage III } \\
\text { Characteristics }\end{array}\end{array}$ & 583 & 74 & 657 \\
\cline { 2 - 4 } Total & 901 & 76 & 977 \\
\hline
\end{tabular}

$$
x^{2}=33.1323, p<.001, \text { d.f. }=1
$$

\section{DISCUSSION}

The statistical analysis of the data of the three primary questions indicated that naive listeners have more difficulty communicating with Stage III speakers than with normal speakers and that listeners did not find Stage III. speech to be as pleasant as normal speech at a statistically significant level $(p<.001)$.

When the listeners were categorized into heterogeneous groups (sex, age, and occupation) to determine if a specific group responded differently than the total homogeneous sample to the question of the communication difficulty of Stage III speech, the data indicated that males and females did not differ in their responses (Table IV); there were no great differences in the responses of persons of different ages (Table V); and most occupation groups did not differ 
greatly from the results of the total sample (Table VI).

Two listeners were not included within the occupation groups as one was retired and the other did not list an occupation. In congruence with the total sample of listeners, al.1 three divisions of heterogeneous groups viewed Stage III speakers to be more difficult to communicate with than normal. speakers.

\section{TABLE IV}

THE PERCENTAGE OF MALES AND FEMALES WHO PERCEIVED

THEY WOULD HAVE DIFFICULTY COMMUNICATING WITH STAGE III SPEAKERS

\begin{tabular}{lcc}
\hline & Males & Females \\
\hline Stage III & $70 \%$ & $67 \%$ \\
\hline
\end{tabular}

TABLE V

THE PERCENTAGE WITHIN AGE GROUPS WHO PERCEIVED

THEY WOULD HAVE DIFFICULTY COMIUNN ICATING WITH STAGE III SPEAKERS

\begin{tabular}{c|ccccc}
\hline & \multicolumn{5}{|c}{ Age } \\
\cline { 2 - 6 } & $20-29$ & $30-39$ & $40-49$ & $50-59$ & $60-69$ \\
\cline { 2 - 5 } Stage III & $62 \%$ & $74 \%$ & $69 \%$ & $71 \%$ & $52 \%$ \\
\hline
\end{tabular}


TABLE VI

THE PERCENTAGE WITHIN OCCUPATION GROUPS WHO PERCEIVED THEY WOULD HAVE DIFFICULTY COMMUNICATING WITH STAGE III SPEAKERS

\begin{tabular}{lcc}
\hline \multicolumn{1}{c}{ Category } & No. in Group & Stage III \\
\hline Medical professional & 6 & $86 \%$ \\
Professional & 9 & $86 \%$ \\
Paraprofessional & 4 & $79 \%$ \\
Housewives & 6 & $76 \%$ \\
Office help & 3 & $76 \%$ \\
Salesmen & 5 & $68 \%$ \\
Skilled workers & 4 & $68 \%$ \\
Morticians & 4 & $50 \%$ \\
Social workers & 5 & $40 \%$ \\
Management & 4 & $39 \%$ \\
\hline
\end{tabular}

Observing the "unpleasant" characteristics attributed to each speaker by the listeners, revealed that the "normal" speakers who had received training and experience in being - an effective speaker, tended to receive fewer "unpleasant" attribute judgments than the other "normal" speakers (Table VII). 
TABLE VII

UNPLEASANT ATTRIBUTE JUDGMENTS OF NORMAL SPEAKERS OUT OF A POSSIBLE 572 RESPONSES BY 52 IISTENERS

\begin{tabular}{|c|c|c|c|c|c|c|c|}
\hline \multirow{2}{*}{ Characteristics } & \multicolumn{7}{|c|}{ Speaker No. } \\
\hline & 1 & 2 & 3 & 6 & 7 & 12 & 14 \\
\hline 1. too loud & 0 & 2 & 0 & 3 & 1 & 5 & 9 \\
\hline 2. too soft & 0 & 0 & 1 & 0 & 0 & 0 & 0 \\
\hline 3. monotone & 0 & 6 & 3 & 4 & 0 & 2 & 1 \\
\hline $\begin{array}{l}\text { 4. } \begin{array}{l}\text { somewhat } \\
\text { whispered }\end{array}\end{array}$ & 0 & 0 & 0 & 0 & 0 & 0 & 0 \\
\hline 5. pitch too high & 0 & 0 & 0 & 0 & 0 & 1 & 1 \\
\hline 6. pitch too low & 0 & 3 & 0 & 0 & 0 & 2 & 0 \\
\hline $\begin{array}{l}\text { 7. somewhat nasal } \\
\text { voice }\end{array}$ & 0 & 1 & 1 & 0 & 0 & 0 & 1 \\
\hline 8. unclear speech & 0 & 0 & 0 & 0 & 0 & 2 & 0 \\
\hline 9. speaks too fast & 0 & 3 & 0 & 2 & 0 & 1 & 10 \\
\hline 10. speaks too slow & 0 & 2 & 6 & 0 & 0 & 2 & 0 \\
\hline $\begin{array}{l}\text { 11. somewhat hoarse } \\
\text { voice }\end{array}$ & 0 & 3 & 0 & 0 & 0 & 0 & 1 \\
\hline Totals & 0 & 20 & 11 & 9 & 1 & 15 & 23 \\
\hline
\end{tabular}

Such normal speakers (number 1, 3, and 7) were Speech Pathologists, who were matched for age and occupation of Stage III speakers. The three Speech Pathologists using Stage III speech in the experimental group had previously received treatment for their stuttering by instruction in Casteel's stuttering management program. The same favorable listener reaction to Speech Pathologists using Stage III speech occurred. Two of the three Speech Pathologists using Stage III speech (number 4 and 9) tended to receive 
fewer "unpleasant" attribute judgments than the other Stage III speakers (Table VIII). Speaker number ll, who was a salesman, received the fewest "unpleasant" attribute judgments, but also received the greatest number of "too loud" responses within the group of Stage III speakers. Perhaps the perceived increased loudness reflected in the tabulation coupled with only one "too soft" lead people in general to be more accepting of this Stage III speech simply on the basis of intensity.

\section{TABLE VIII}

UNPLEASANT ATTRIBUTE JUDGMENTS OF STAGE III SPEAKERS OUT OF A POSSIBLE 572 RESPONSES BY 52 LISTENERS

\begin{tabular}{|c|c|c|c|c|c|c|c|}
\hline \multirow{2}{*}{ Characteristics } & \multicolumn{7}{|c|}{ Speaker No. } \\
\hline & 4 & 5 & 8 & 9 & 10 & 11 & 13 \\
\hline 1. too loud & 0 & 0 & 0 & 0 & 0 & 4 & O \\
\hline 2. too soft & 35 & 32 & 37 & 5 & 17 & 1 & 25 \\
\hline 3. monotone & 13 & 10 & 36 & 25 & 23 & 26 & 27 \\
\hline $\begin{array}{l}\text { 4. somewhat } \\
\text { whispered }\end{array}$ & 35 & 32 & 24 & 5 & 13 & 1 & 25 \\
\hline 5. pitch too high & 0 & 0 & 0 & 0 & 0 & 1 & 1 \\
\hline 6. pitch too low & 7 & 4 & 11 & 4 & 1 & 4 & 7 \\
\hline $\begin{array}{l}\text { 7. somewhat nasal } \\
\text { voice }\end{array}$ & 3 & 6 & 13 & 13 & 7 & 14 & 19 \\
\hline 8. unclear speech & $14^{\circ}$ & 19 & 27 & 37 & 27 & 20 & 39 \\
\hline 9. speaks too fast & 4 & 3 & 1 & 2 & 42 & 8 & 9 \\
\hline 10. speaks too slow & 3 & 3 & 29 & 17 & 0 & 2 & 5 \\
\hline $\begin{array}{l}\text { 11. somewhat hoarse } \\
\text { voice }\end{array}$ & 0 & 10 & 3 & 2 & 3 & 2 & 4 \\
\hline Totals & 114 & 119 & 181 & 110 & 133 & 83 & 161 \\
\hline
\end{tabular}


To determine members representing the experimental group and members representing the control group, the Jewish Hospital Voice Profile was used. Because Stage III speakers would be doing some specific things differently when talking than "normal" speakers, this group was evaluated differently than the control group in some scales of the Jewish Hospital Voice Profile. The normal speakers had to receive a rating of "l" on the Openness of the Laryngeal Cavity, Pitch, Resonating Cavity, Vocal Range, Rate, and Intensity scales of the Jewish Hospital Voice Profile to be selected as a member of the control group. The Stage III speakers were only judged on the Resonating Cavity, the Openness of the Laryngeal Cavity, and the Ptich scales. They had to receive a rating of "l" on the Resonating Cavity scale, a "-2" on the Openness of the Laryngeal Cavity scale, and a "+2, 1 , or -2 " on the Pitch scale to be a member of the experimental group. They were not judged on the Vocal Range, Rate, and Intensity scales of the Jewish Hospital Voice Profile. To equally evaluate Stage III speakers with normal speakers, Stage III speakers should have also been judged on the Vocal Range, Rate, and Intensity scales as the normal speakers.

Stage III speech is characterized by breathiness and imprecise articulation. Listeners identified "unclear speech," or imprecise articulation, most often as an unpleasant attribute of Stage III speech (Table IX). 
"Somewhat whispered," or breathiness, was ranked fourth among the unpleasant attributes of Stage III speech (Table IX). Because of the breathiness present in Stage III speech, the vocal folds are more relaxed, thus acoustically resulting in a somewhat lower pitch (Fairbanks 1940). Murphy (1964) stated that a monotonous voice is likely to occur in persons speaking habitually at pitch levels which are unnaturally low. In section three of the speaker evaluation form, monotone was ranked second among the characteristics which listeners attributed to their unpleasantness rating of Stage III speech (Table IX). The lowered pitch caused by the addition of breathiness most. likely restricted the Stage III speaker's vocal range and attributed to the listeners' "unpleasantness" ratings of Stage III speech.

TABLE IX

TOTAL NUMBER OF LISTENER IDENTIFICATIONS OF UNPLEASANT ATTRIBUTES OF ALL STAGE III SPEAKERS

Characteristic

Unclear speech . . . . . . . Monotone ............ Too soft.............

Somewhat whispered . . . . . .

Somewhat nasal voice.......

Speaks too fast . . . . . . .

Speaks too slow ..........

Pitch too low ..........

Somewhat hoarse voice .......

Too loud ..............

Pitch too high..........
No. of Listener Responses

183

160

152

135

75

69

59

38

24 
Breathiness is often associated with weak vocal intensity (Fairbanks 1940). Reduced intensity could be considered a secondary characteristic of Stage III speech. Listeners ranked the voice characteristic "too soft" in section three of the speaker evaluation form third among the characteristics which attributed to their unpleasantness ratings of Stage III speech (Table IX).

Listeners had a little more difficulty pinpointing "somewhat whispered" as being a characteristic of Stage III speech than "unclear speech." They identified the voice characteristics of "monotone" and "too soft" as higher ranking attributers to the unpleasantness of Stage III speech than breathiness, or "somewhat whispered." Because "monotone" and "too soft" are indirectly related to the breathiness present in Stage III speech, it can be concluded that listeners had more difficulty identifying "breathiness" as a characteristic of Stage III speech than in the identification of imprecise articulation as a characteristic of Stage III speech.

The results of this study indicated listeners would have difficulty communicating with Stage III speakers and that listeners did not find Stage III speech to be as pleasant as normal speech. It must be observed that the person using Stage III speech is modifying specific dimensions of normal speech to be fluent and has not reached the final step of the program. The primary goal of each stage 
within Casteel's stuttering management program is to be fluent, rather than to use "normal" speech. Speakers using Stage III speech have chosen fluent speech rather than stuttering. Stage. IV, or easy talking, more closely approximates normal speech patterns. This manner of speaking might be more pleasing to the listener and easier to communicate with than Stage III. speech.

Listener judgment of a fluent speech pattern which approximates normal speech has been the concern of Perkins et al. in several studies (1974). Listeners judged speakers in the final step of his most recent management. program to be no different than normal speakers on the basis of fluency, rate, and prosody. The results of this study cannot be compared to Perkins et al. (1974) because the subjects in their experiment had completed the stuttering management program, while the subjects in this study were still in the modification process of fluency.

In one of Perkins' stuttering management programs (Curlee and Perkins 1973), some of the subjects sacrificed prosody for fluency by using slow rates with monotonous inflection. Curlee and Perkins (1973) observed that for severe stutterers this trade-off may have some merit, but not all would be willing to accept it. Even though a person who stutters may be doing something different from normal speaking to remain fluent, he still risks social ostracization. When a speaker has the choice of stuttering or being 
fluent by means of using, a manner of speaking that varies somewhat from "normal" speech, he will most likely choose the manner of speaking which evokes the least amount of listener penalty. 


\section{CHAPTER V \\ SUMIARY AND IMPIICATIONS}

\section{SUMMARY}

Because communication involves both a sender of messages and a receiver of messages, each person could influence the other's' feelings about speaking and listening. The reactions of each member of this communication network will determine how communication will flow in the future. With an understanding of the feedback system between speakers and listeners, researchers have attempted to design management programs which allow the speaker who stutters to develop a new pattern of speech which does not hinder his communication efforts. Fluency is the primary consideration, and normalcy of speech is second.

In Casteel's stuttering management program, a person moves through four stages of speaking to be fluent. The client learns to sacrifice specific components of speech and these components are systematically reinstated while fluency in reading, monologue, and dialogue are maintained. Specifically, the purpose of this study was to determine if breathy and imprecisely articulated speech (Stage III) interferes with the speaker's ability to 
communicate. The questions to be answered by this study were:

1. Will the u'se of breathy and imprecisely articulated speech (Stage III) interfere with the listener's ability to communicate with that speaker?

2. Do listeners perceive Stage III speech to be as pleasant as "normal" speech?

3. Do listeners find specific voice characteristics of Stage III speech (breathiness and imprecise articulation) attributed to their rating of "unpleasant"?

The subjects were 7 male "stutterers" who had received instruction in Casteel's stuttering management program and were judged to use a "good" or "excellent" fluent Stage III and 7 male "normal" speakers, who received a "l" on specific. scales of the Jewish Hospital Voice Profile by trained judges. The control group was matched for age and occupation of each subject in the experimental group.

The subjects were tape-recorded while reading a passage from Narcissus and Goldmund (Hesse 1968) and were dubbed onto a second tape in a sequence determined by entry into a table of random numbers.

Listeners, who represented a wide variety of backgrounds, occupations, and age, evaluated each speaker on (1) their ability to communicate with that speaker, (2) the pleasantness of the speaker's voice on a scale of one to five, and (3) the specific characteristics that attributed to their rating of four or five on the "unpleasantness" side of the scale. 
The findings indicated that naive listeners would have more difficulty communicating with Stage III speakers than normal speakers and that listeners did not find Stage III speech to be as pleasant as normal speech at a statistically significant level. Listeners were also able to identify the specific characteristics of Stage III speech (breathiness and imprecise articulation) from other non-Stage III characteristics at a statistically significant level. When breaking down the homogeneous sample into heterogeneous groups of sex, age, and occupation, Stage III speakers were still viewed to be more difficult to communicate with than "normal" speakers within each group.

\section{IMPLICATIONS}

\section{Clinical}

The conclusions of this study seem to indicate that stutterers who are fluent, but are doing something different from normal speaking, may still be penalized by their listeners. Probably the person previously has been socially ostracized by his listeners for stuttering and so took initiative to change his speech patterns. When he discovers that he can do specific things to be fluent, he muşt make the choice between stuttering and fluency. He will most likely choose the manner of speaking which evokes the least amount of listener penalty. If he is successful using Stage III speech in situations in which he previously 
stuttered, he will probably continue to build upon these successes by using Stage III speech in more situations.

\section{$\underline{\text { Research }}$}

A similar replication of this study comparing Stage IV speech to normal speech would be suggested, as Stage IV speech more closely approximates normal speech. Stutterers completing the program would be using Stage IV speech to maintain fluency in most or all speaking situations.

-To determine whether fluent, but not normal speaking, or dysfluent speech evokes the greatest listener penalty, this study could be conducted using fluent Stage III speakers and dysfluent Stage III speakers, fluent Stage III speakers and dysfluent speakers not involved with Casteel's stuttering management program, fluent Stage IV speakers and dysfluent Stage IV speakers, or fluent Stage IV speakers and dysfluent speakers not involved with Casteel's stuttering management program. As an additional part of the study, it would be interesting to determine if listeners identified Stage III or IV speakers as stutterers. The experimental subjects matched against the normal speakers should be evaluated on the same scales of the Jewish Hospital Voice Profile. As a result, voice characteristics, such as slow rate or nasality, which are not specific to Stage III or IV speech, could not be attributed to an "unpleasant" rating. 


\section{A SELECTED BIBLIOGRAPHY}

Addington, D., The relationship of selected vocal characteristices to personality perception. Speech Monographs, $35,492-503$ (1968).

Andrews, G., and Ingham, R., Stuttering: Considerations in the evaluations of treatment. British $\mathrm{J}$ of Dis. of Communication, 6, 129-138 (1971a).

Stuttering: The quality of fluency after treatment. $\mathrm{J}$ of Communication Dis., 4, 279-288 (1971b).

Berlin, S., and Berlin, C., Acceptability of stuttering control patterns. J Speech Hearing Dis., 29, 436-441 (1964).

Berwick, N., Stuttering in response to photographs of certain selected listeners. In W. Johnson (Ed.), Stuttering in Children and Adults. Minneapolis: Univ. of Minnesota Press (1955).

Bloodstein, 0., Stuttering as an anticipatory struggle reaction. In J. Eisenson (Ed.), Stuttering: A Symposium. New York: Harper and Row, Inc. (1958).

Stuttering and normal nonfluency--a continuity hypothesis. British J of Dis. of Communication, 5, 30-39 (1970).

, Jaeger, W., and Tureen, J., A study of the diagnosis of stuttering by parents of stutterers and nonstutterers. J Speech Hearing Dis., 17, 308-315 (1952).

Boehmler, R., Listener responses to non-fluencies. J Speech Hearing Res., 1, 132-141 (1958).

Casteel, R., The modification of stuttering through a series of discrimination tasks. Paper presented at ASHA convention, Las Vegas (November 6, 1974).

Curlee, R., and Perkins, W., Conversational rate control therapy for stuttering. J Speech Hearing Dis., 34 , 245-250 (1969). 
Curlee, R., and Perkins, W., Effectiveness of a DAF conditioning program for adolescent and adult stutterers. Behav. Res. and Therapy, 11, 395-401 (1973).

Diehl, C., and McDonald, E., Effect of voice quality on communication. J Speech Hearing Dis., 21, 233-237 (1956).

Fairbanks, G., Voice and Articulation Drillbook. New York: Harper and Brothers (1940).

Few, I., and Lingwall, J., A further analysis of fluency within stuttered speech. J Speech Hearing Res., 15, 356-363 (1972).

Giolas, T., and Williams, D:, Children's reactions to nonfluencies in adult speech. J Speech Hearing Res., I, 86-93 (1958).

Goldiamond, I., Stuttering and fluency as manipulable operant response classes. In I. Krasner and L. Ullman (Eds.), Research in Behavior Modification: New Developments and Implications. New York: Holt, Rinehart and Winston (1965).

Gregory, H. (Ed.), Learning Theory and Stuttering Therapy. Evanston: Northwestern University Press (1968).

Hesse, H., Narcissus and Goldmund. New York: Farrar, Straus, and Giroux, Inc. (1968).

Johnson, W. (Ed.), Stuttering in Children and Adults. Minneapolis: University of Minnesota Press (1955).

, Darley, F., and Spriestersbach, D., Diagnostic Methods in Speech Pathology. New York: Harper and Row, Inc. (1963).

Love, L., and Jeffress, I., Identification of brief pauses in the fluent speech of stutterers and nonstutterers. J Speech Hearing Res., 14, 229-240 (1971).

McDonald, E., and Frick, J., Store clerks' reaction to stuttering. J Speech Hearing Dis., 19, 306-311 (1954).

Murphy, A., Functional Voice Disorders. New Jersey: Prentice-Hall, Inc. (1964).

Perkins, $W_{.}$, Speech Pathology: An Applied Behavioral Science. St. Louis: C. V. Mosby Co. (1971). 
Perkins, W., Replacement of stuttering with normal speech: I. Rationale. I Speech Hearing Dis., 38, 283-294 (i973a).

Replacement of stuttering with normal speech: II. Clinical procedures. J Speech Hearing Dis., 38, $295-303(1973 b)$.

Tape sent to Portland State University explaining his stuttering management program (1973c).

, Rudas, J., Johnson, L., Michael, W., and Curlee, R., Replacement of stuttering with normal speech: III. Clinical effectiveness. J Speech Hearing Dis. , 39, 416-428 (1974).

Ptacek, P., and Sander, E., Breathiness and phonation length. J Speech Hearing Dis., 28, 267-272 (1963).

Rosenberg, S., and Curtiss, J., The effect of stuttering on the behavior of the listener. I Abnormal and Social Psy., 49, 355-361 (1954).

Ryan, B., The construction and evaluation of a program for modifying stuttering behavior. Unpublished doctoral dissertation, University of Pittsburgh (1964).

Sander, E., Frequency of syllable repetition and "stutterer" judgments. I Speech Hearing Dis., 28, 19-30 (1963).

Talking plainly about stuttering: Guidelines for the beginning clinician. Central States Speech J.; 21, 248-254 (1970).

Sheehan, J., Stuttering as a self-role conflict. In H. Gregory (Ed.), Learning Theory and Stuttering Therapy. Evanston: Northwestern University Press (1968).

, Hadley, R., and Gould, E., Impact of authority on stuttering. J of Abnormal Psy., IXII, 290-293 (1967).

Soderberg, G., Delayed auditory feedback and stuttering. J Speech Hearing Dis., 33, 260-267 (1968).

Steer, M., and Johnson, W., An objective study of the relationship between psychological factors and the severity of stuttering. J Abnormal and Social Psy., 31, 36-46 (1936).

Van Riper, C., Speech Correction: Principles and Methods. Fourth Ed., Englewood Cliffs, New Jersey: PrenticeHall (1963). 
Van Riper, C., The Nature of Stuttering. Englewood Cliffs, New Jersey: Prentice-Hall, Inc. (1971).

- The Treatment of Stuttering. Englewood Cliffs, New Jersey: Prentice-Hall, Inc. (1973).

Wendahl, R., and Cole, J., Identification of stuttering during relatively fluent speech. J Speech Hearing Res., 4, 281-286 (1961).

Williams, D., A point of view about stuttering. J Speech Hearing Dis., 22, 390-397 (1957).

- and Kent, L., Listener evaluations of speech interruptions. J'Speech Hearing Res., 1, 124-131 (1958).

Wilson, F., The voice-disordered child: A descriptive approach. Language; Speech, and Hearing Services in Schools, 1 (4), 14-22 (1971).

Young, M., Identification of stutterers from recorded samples of their fluent. speech. I Speech.Hearing Res., $7,302-303(1964)$. 
SHDICNFddV 


\section{APPENDIX A}

\section{INSTRUCTIONS TO JUDGES}

\section{Evaluating Stage III Speakers}

You will hear several speakers using Stage III speech. After each speaker, rate his Stage III speech as "poor," "good," or "excellent." Examples of a "poor" rating might be indicative of an inconsistent use of Stage III speech, use of Stage II or IV speech, or inappropriate use of breathiness and imprecise articulation. If you rated the speakèr's Stage III speech as "poor," please list the chief reason or reasons for the "poor" rating.

There are to be no interferences in the speaker's speech. 


\section{TIE JEIYISI IIDSPITAL VOICE PROFILE}

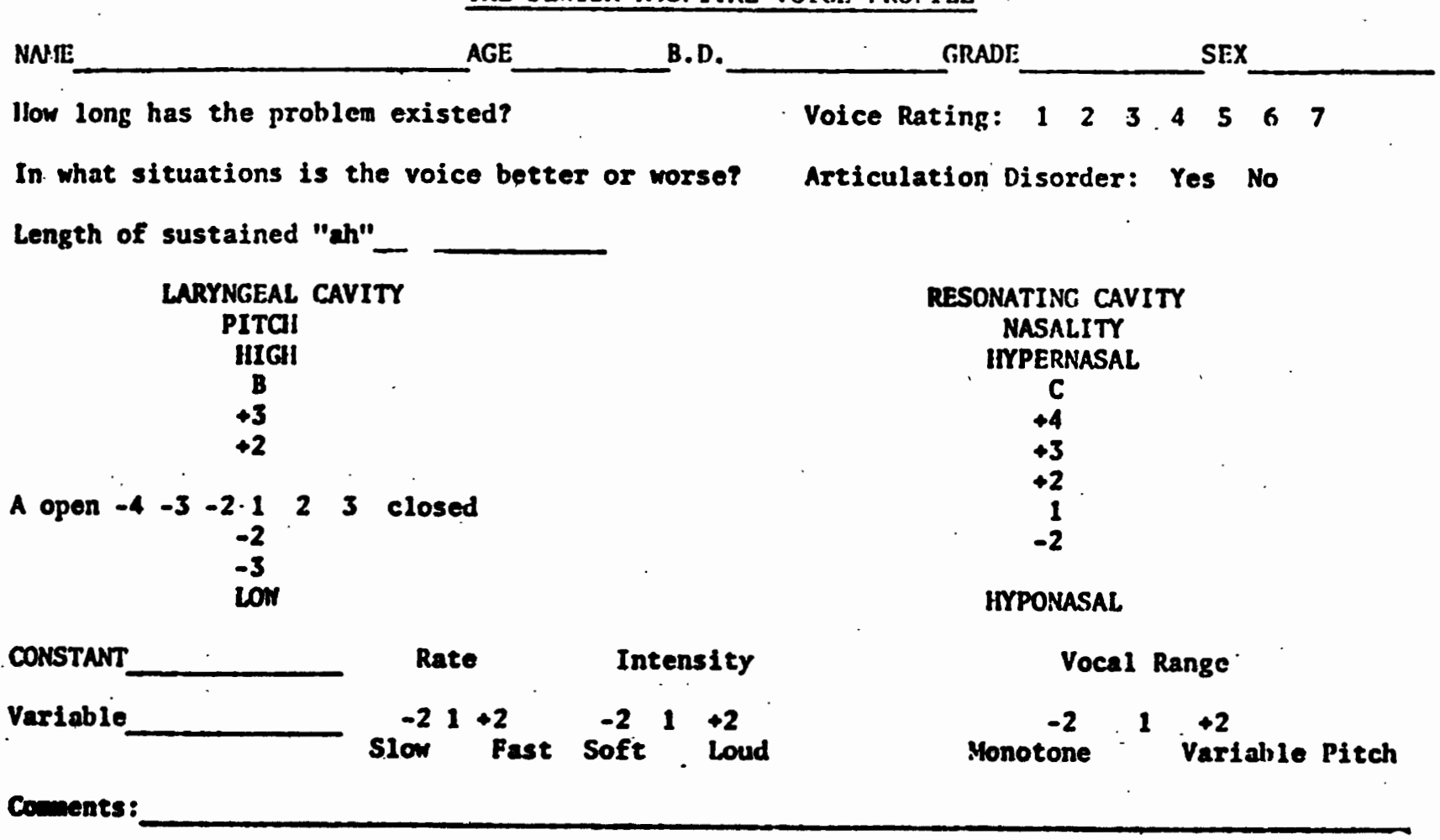


The Jewish Hospital Voice Profile was developed by Frank B. Wilson (1971) as a descriptive approach to define voice deviations. The characteristics of voice that will often be changed during management are described. At the top of the Voice Profile sheet there is a section for "identifying information" and a brief statement of case history. In the upper right-hand corner of the profile, the section called "Voice Severity" is used to describe on a comparative basis the voice as. it affects the clinician. A rating of "l" means the problem is barely perceptible; a "7" means the problem significantly interferes with communication.

The Laryngeal Cavity scale, line A, deals with the open and closed portion of the vocal folds. At the extreme left, -4 would mean the folds are totally open. To the extreme right of line $A$, +3 represents extreme tension, with inability of the individual to sustain normal vocal fold vibration. Between these extremes, moving from left to right, -3 represents the production of a whisper and -2 represents breathiness which generally is characterized by turbulence and some friction. A normal voice is represented by 1. The +2 side represents a voice which is characterized by much tension.

The Pitch scale, line $B$, is primarily a social judgment. The rating of +3 at the high and -3 at the low denote those pitches which are sufficiently deviant to cause 
the individual to lose sexual identity if this judgment alone is made on voice. Minus 2 and plus 2 represent deviations of 'pitch that cause concern primarily on the part of the critical listener, usually the speech clinician. Under the section Resonating Cavity, line C, -2 represents the voice with a lack of nasal resonance in the production of normally nasalized sounds. One represents normal, +2 represents assimilation nasality, +3 represents nasalization of vowels with some shading of a nasal nature to the consonants, and +4 represents nasality of all sounds with frequent nasal distortions of consonant sounds.

The Rate, Intensity, and Vocal Range sections are additional components of voice which the Jewish Hospital Voice Profile lists. On the Rate scale, -2 is designated as slow, 1 as normal, and +2 as fast. On the Intensity scale, -2 is designated as soft, 1 as normal, and +2 as loud. Monotone is represented by -2 on the Vocal Range scale, 1 as normal, and +2 as variable pitch. 


\begin{abstract}
APPENDIX C
INSTRUCTIONS TO JUDGES
\end{abstract}

Evaluating Voice of Control Group

You will hear several speakers. Using the sections of the Openness of the Laryngeal Cavity, Pitch, Resonating Cavity, Vocal Range, Rate, and Intensity on the Jewish Hospital Voice Profile, evaluate each speaker's voice. Note any comments. 


\section{APPENDIX D \\ INSTRUCTIONS TO JUDGES \\ Evaluating Voice Quality of \\ Stage III Speakers}

You will hear several speakers using Stage III speech. Using the Openness of the Laryngeal Cavity, Pitch, and Resonating Cavity scales on the Jewish Hospital Voice Profile, evaluate each speaker's voice. Note any comments. 


\section{APPENDIX E}

\section{SELECTED READING PASSAGE}

Much rain, much snow had fallen on Goldmund. One day he climbed uphill through a sparse beech forest already light green with buds. From the mountain ridge he saw a new landscape lying at his feet; it gladdened his eyes and a flood of expectations, desires, and hopes gushed through his heart. For several days he had known that he was close to this region; he had been looking forward to it. Now, during this noon hour, it came as a surprise and his first visual impression confirmed and strengthened his expectations (Hesse 1968). 
APPENDIX F

INSTRUCTIONS TO LISTENERS

Please list your age, sex, and occupation on the front page of the sheets you have. Do this and then turn the page.

You will hear several speakers reading the same passage. Listen carefully to each speaker, as you will only be able to hear each speaker once. After listening to each speaker answer the question in Section one: "Would his speech make it difficult for you to carry on a conversation with this person?" by circling "yes" or "no." If you responded by circling "yes," answer the question "What aspects of his speech would interfere with being able to carry on a conversation with this person?" in the space provided.

Next complete Section two by rating the speaker as being "pleasant" or "unpleasant" to listen to by circling a number from one to five on your sheet. "One" represents "very pleasant" to listen to and "five" represents "very unpleasant" to listen to. If you rated the speaker a four or five, please complete Section three. 
In Section three check which voice characteristic or characteristics contributed to your rating of four or five. Going down the list, these include:

1. too loud

2. too soft

3. monotone

4. somewhat whispered

5. pitch too high

6. pitch too low

7. somewhat nasal voice

8. unclear speech

9. speaks too fast

10. speaks too slow

11. Somewhat hoarse voice

Be sure to use a new sheet for each speaker. 
APPENDIX G

\section{LISTENER EVALUATION OF SPEAKER SHEET}

Section 1 -- CIRCLE ONE

Would his speech make it difficult for you to carry on a conversation with this person?

YES NO

If YES, what aspects of his speech would interfere with being able to carry on a conversation with this person?

Section 2 -- CIRCLE ONE

1

2. 3

4

5

very pleasant

very unpleasant

IF YOU RATED THIS SPEAKER 4 OR 5, COMPLETE SECTION 3 BELOW

Section 3

Check which voice characteristic or characteristics that attributed to your rating of 4 or 5 above.

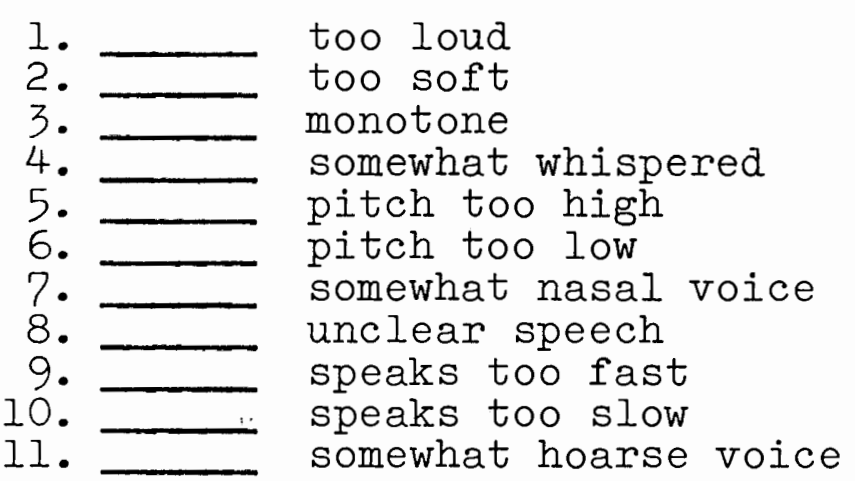

